\title{
Sistem Pengendalian dan Pencegahan Infeksi Rumah Sakit Menggunakan Bootstrap
}

\author{
Arfan Sansprayada*)1), Kartika Mariskhana ${ }^{2)}$, Riva Abdillah Aziz ${ }^{3)}$ \\ ${ }^{12)}$ Universitas Bina Sarana Informatika \\ 3) Sekolah Tinggi Manajemen Informatika dan Komputer Nusa Mandiri \\ ${ }^{*}$ Correspondence author: arfan.anp@bsi.ac.id, DKI Jakarta, Indonesia
}

\begin{abstract}
Abstrak
Penelitian ini bertujuan untuk mengeksplorasi secara mendalam pelaksanaan pencegahan dan pengendalian infeksi untuk meningkatkan mutu pelayanan di salah satu rumah sakit daerah tangerang selatan. Hasil penelitian menunjukkan dari beberapa bagian, yaitu : pelaksanaan pencegahan dan pengendalian infeksi yang dibentuk dari sub tema monitoring evaluasi pencegahan infeksi, pendataan kejadian infeksi dan mencegah terjadinya infeksi, peningkatan pengetahuan tentang infeksi yang dibentuk dari peningkatan pengetahuan tentang infeksi, manfaat pelaksanaan PPI yang dibentuk dari sub tema manfaat untuk petugas kesehatan dan manfaat untuk pelayanan kesehatan, kendala dalam penerapan PPI yang dibentuk dari sub tema kurang tersedianya sarana dan prasarana, kesadaran petugas kesehatan yang masih kurang dan pencatatan kasus infeksi yang tidak berkelanjutan, alternatif pemecahan masalah yang dibentuk dari improvisasi alat, memberikan bimbingan ulang kepada petugas dan memberikan teguran langsung, harapan untuk pelaksanaan kegiatan PPI yang lebih efektif yang dibentuk dari sub tema harapan untuk sesama petugas kesehatan dan harapan untuk pihak rumah sakit.
\end{abstract}

Kata Kunci: Sistem, Informasi, Aplikasi Bootstrap

\begin{abstract}
This study aims to explore in depth the implementation of infection prevention and control to improve the quality of service in one of the southern Tangerang hospitals. The results of the study showed several sections, namely: implementation of infection prevention and control which was formed from sub-themes monitoring evaluation of infection prevention, collecting data on infection events and preventing infection, increasing knowledge about infections formed from increasing knowledge about infections, benefits of implementing PPI that were formed from sub-themes of benefits for health workers and benefits for health services, constraints in the application of PPI formed from sub-themes of the lack of available facilities and infrastructure, awareness of health workers who are still lacking and recording cases of infections that are not sustainable, alternative solutions to problems that are formed from improvised tools, provide re-guidance to officers and provide direct reprimands, hopes for the implementation of more effective PPI activities which are formed from sub-themes of expectations for fellow health workers and expectations for hospitals.
\end{abstract}

Keywords: System, Information, Application, Bootstrap

\section{PENDAHULUAN}

Pencegahan dan pengendalian infeksi dirumah sakit dan fasilitas pelayanan kesehatan merupakan suatu upaya kegiatan untuk meminimalkan atau mencegah terjadinya infeksi pada pasien, petugas, pengunjung dan masyarakat sekitar rumah sakit. Salah satu program pencegahan dan pengendalian infeksi (PPI) adalah kegiatan surveilans, disamping adanya kegiatan lain seperti pendidikan dan latihan,kewaspadaan isolasi serta kegiatan surveilans infeksi difasilitas pelayanan kesehatan merupakan salah satu kegiatan yang penting dan 
luas dalam program pengendalian infeksi dan suatu hal yang harus dilakukan untuk mencapai keberhasilan dari program PPI.

Surveilans Infeksi Rumah Sakit (RS) adalah suatu proses yang dinamis, sistematis, terusmenerus dalam pengumpulan data, identifikasi, analisis dan interprestasi dari data kesehatan yang penting pada suatu populasi spesifik yang didiseminasikan secara berkala kepada pihak-pihak yang memerlukan untuk digunakan dalam perencanaan,penerapan dan evaluasi suatu tindakan yang berhubungan dengan kesehatan. Mengenai pendataan surveilans infeksi rumah sakit menjadi fokus utama penulisan penelitian ini. Penelitian yang dilakukan mengacu pada pelaksanaan langkah-langkah pencegahan dan pengendalian infeksi pada pasien di rumah sakit.

Rumah Sakit Insan Permata yang berada di kota Tangerang selatan, adalah lokasi yang dipilih oleh tim penulis untuk melakukan penelitian. Kegiatan medis yang ada di sana selama ini berjalan lancar dengan di tangani oleh tim medis yang profesional. Pencatatan data infeksi yang masih dilakukan secara manual, akan menjadi permasalahan sendiri apabila tidak ditangani dengan tepat. Oleh karena itu, kami ingin menciptakan sebuah sistem informasi yang dapat mendeteksi dan mencegah suatu infeksi pasien yang ada di RS. Insan Permata kota Tangerang selatan.

\section{METODE}

Pengumpulan data penelitian ini menggunakan beberapa teknik yaitu :

1. Observasi

Melakukan pengamatan dan pengumpulan data dengan melihat secara langsung obyek penelitian yang dituju, terutama aktivitas dan kejadian yang sedang berjalan. Seperti perawat melakukan tindakan kepada pasien seperti memasang infus, tensi darah, injeksi obat dan lain sebagainya. Setelah itu ada perawat ataupun pasien terkena infeksi maka akan di tangani dan bisa di deteksi apa penyebab infeksi dan cara menanggulanginya.

2. Interview

Informasi serta data yang diperoleh dengan cara bertanya kepada petugas secara langsung pada staff rumah sakit maupun pegawai rumah sakit RSU Insan Permata yang ditugaskan disana. Perawat pelaksana merupakan salah satu entitas utama dalam sistem yang di teliti. Dan di PPI RSU Insan Permata mempunyai sebuah tim PPI terdiri IPCLN dan IPCN. IPCLN terdiri dari kepala ruangan dan IPCN adalah perawat dan dokter yang mempunyai sertifikat PPI. 


\section{Studi Pustaka}

Memperlajari dan memahami landasan teori yang terkait dengan masalah yang akan dibahas serta metode penelitian akan dilakukan seperti pengambilan data, menganalisis perancangan penelitian dan menganalisis perancangan sistem.

Menurut (Hamim Tohari, 2014 : 2), yang mengungkapkan pendapat bahwa "Sistem adalah kumpulan atau himpunan dari unsur atau variabel-variabel yang saling terkait, saling berinteraksi, dan saling tergantung satu sama lain untuk mencapai tujuan”. Selain itu sistem juga dapat didefinisikan sebagai sekumpulan objek-objek yang slaing berelasi dan berinteraksi, serta hubungan antar objek bisa dilihat sebagai satu kesatuan yang dirancang untuk mencapai satu tujuan yang telah ditetapkan. Menurut kadir didalam (2014:61) Sistem adalah sekumpulan elemen yang saling terkait atau terpadu yang dimaksudkan untuk mencapai suatu tujuan.

Menurut Gordon B Davis (2015:8) Informasi adalah data yang telah diolah menjadi suatu bentuk yang penting bagi si penerima dan mempunyai nilai nyata yang dapat dirasakan dalam keputusan - keputusan yang sekarang atau keputusan - keputusan yang akan datang.

Menurut Alter dalam Kadir (2014:9) "Sistem informasi adalah kombinasi antara prosedur kerja, informasi, orang, dan teknologi informasi yang diorganisasikan untuk mencapai tujuan dalam sebuah organisasi”.

Menurut Sukamto dan Shalahuddin (2013:133) UML (unified modeling language) yaitu standarisasi bahasa pemodelan untuk pembangunan perangkat lunak yang dibangun dengan menggunakan teknik pemrograman berorientasi objek.

UML merupakan bahasa visual untuk permodelan dan komunikasi mengenai sebuah sistem dengan menggunakan diagram dan teks-teks pendukung.Diagram berbentuk grafik yang menunjukkan simbol elemen model yang disusun untuk mengilustrasikan bagian atau aspek tertentu dari sistem. Sebuah diagram merupakan bagian dari suatu view tertentu dan ketika digambarkan biasanya dialokasikan untuk view tertentu. Adapun jenis diagram antara lain :

1. Use Case Diagram

Menurut Sukamto dan Shalahuddin (2013:155) Use case atau diagram use case merupakan permodelan untuk kelakukan (behavior) sistem informasi yang akan dibuat. Use case mendeskripsikan sebuah interaksi antara satu atau lebih aktor dengan sistem informasi yang akan dibuat. 
Menurut Sukamto dan Shalahuddin (2013:161) "Diagram aktivitas atau activity diagram menggambarkan workflow ( aliran kerja) atau aktivitas dari sebuah sistem atau proses bisnis atau menu yang ada pada perangkat lunak."

3. Class Diagram

Menurut Sukamto dan Shalahuddin (2013:141) "Diagram kelas atau class diagram menggambarkan struktur sistem dari segi pendefinisian kelas-kelas yang akan dibuat untuk membangun sistem. Kelas memiliki apa yang disebut atribut dan metode atau operasi."

4. Sequence Diagram

Menurut Sukamto dan Shalahuddin (2013:165) Diagram sekuen menggambarkan kelakuan objek pada use case dengan mendeskripsikan waktu hidup objek dan message yang dikirimkan dan diterima antar objek. Oleh karena itu untuk menggambarkan diagram sekuen maka harus diketahui objek-objek yang terlibat dalam sebuah use case beserta metode-metode yang dimiliki kelas yang diintansiasi menjadi objek itu.

Sukamto dan Shalahuddin (2013:50), Entity Relationship Diagram (ERD)adalah Bentuk paling awal dalam melakukan perancangan basis data relasional. Permodelan basis data yang paling banyak digunakan adalah Entity Relationship Diagram (ERD). ERD dikembangkan berdasarkan teori himpunan dalam bidang matematika. ERD digunakan untuk permodelan basis data relasional. Sehingga jika penyimpanan basis data menggunakan ERD, model dapat diuji dengan mengabaikan proses yang dilakukan.

Website adalah sejumlah halaman web yang memiliki topik saling terkait, terkadang disertai pula dengan berkas-berkas gambar, video, atau jenis-jenis berkas lainnya.

Supono dan Putratama (2016:109) CodeIgniter adalah aplikasi open source berupa framework dengan model MVC (Model, View, Controller) untuk membangun website dinamis dengan menggunakan PHP”

Menurut Abdulloh (2016:157) Bootstrap merupakan salah satu framework CSS yang sangat populer di kalangan pecinta pemrograman website. Dengan menggunakan bootstrap, proses desain website tidak dibuat dari nol, sehingga proses desain website lebih Menuruti Iskandar (2009:1) Internet atau interconnected network adalah sebuah sistem komunikasi global yang menghubungkan computer-komputer dan jaringan terhubung secara langsung maupun tidak langsung ke beberapa jalur utama yang disebut internet backbone. Masing-masing dibedakan anatar satu dengan yang lainnya menggunakan 
unique name yang disebut alamat 32 bit. contoh alamat ip adalah 202.155.4.230 Computer dan jaringan dengan berbagai platform (unix, linux, windows,mac ,dan lain lain;masing masing mempunyai perbedaan dan ciri khas) dapat bertukar informasi dengan adanya sebuah protocol standar yang dikenal dengan nama TCP/IP (Transmission Control Protocol /Internet Protocol). TCP/IP tersusun atas empat layer, yaitu network access, internet, host to -host transport dan application setiap layer tersebut memliki protokolnya

PHP adalah salah satu bahasa pemrograman script yang dirancang untuk membangun aplikasi web. Ketika dipanggil dari web browser, program yang ditulis dengan PHP akan di-parsing di dalam web server oleh interpreter PHP dan diterjemahkan kedalam dokumen HTML, yang selanjutnya akan ditampilkan kembali ke web browser. Karena pemrosesan program PHP dilakukan di lingkungan web server,PHP dikatakan sebagai bahasa sisi server (server-side). (Samudera, 2015).

Menurut Faizal dan Irnawati (2015:4) mendefinisikan MySQL merupakan perangkat lunak sistem manajemen berbasis data SQL (bahasa Inggris : database management system) atau DBMS yang multithread dan multi-user, dengan sekitar 6 (enam) juta instalasi di seluruh dunia. MySQL merupakan software sistem manajemen database (Database Management System - DBMS) . Pemrograman PHP juga sangat mendukung dengan database MySQL.

MySQL adalah Relational Database Management System (RDBMS) yang didistribusikan secara gratis dibawah lisensi GPL (General Public License). Dimana setiap orang bebas untuk menggunakan MySQL, namun tidak boleh dijadikan produk turunan yang bersifat komersial. MySQL sebenarnya merupakan turunan salah satu konsep utama dalam database sejak lama, yaitu SQL (Structured Query Language). SQL adalah sebuah konsep pengoperasian database, terutama untuk pemilihan atau seleksi dan pemasukan data, yang memungkinkan pengoperasian data dikerjakan dengan mudah secara otomatis. Keandalan suatu database (DBMS) dapat diketahui dari cara kerja optimizer-nya dalam melakukan proses perintah-perintah SQL, yang dibuat oleh user maupun program-program aplikasinya. Sebagai database server, MySQL dapat dikatakan lebih unggul dibandingkan database server lainnya dalam query data. Hal ini terbukti untuk query yang dilakukan oleh single user, kecepatan query MySQL bisa sepuluh kali lebih cepat dari PostgreSQL dan lima kali lebih cepat dibandingkan Interbase.

Menurut Baskoro (2013:16) Xampp adalah salah satu software server yang bisa berjalan diatas sistem operasi seperti windows, apple, dan linux. Melalui xampp ini aplikasi website atau CMS bisa dijalankan, termasuk joomla, drupal, wordpress, dan lainnya. 


\section{HASIL DAN PEMBAHASAN}

Berikut ini adalah Use Case Diagram yang menggambarkan sistem informasi Formulir dan laporan Rumah Sakit Umum Insan Permata berikut gambarannya:

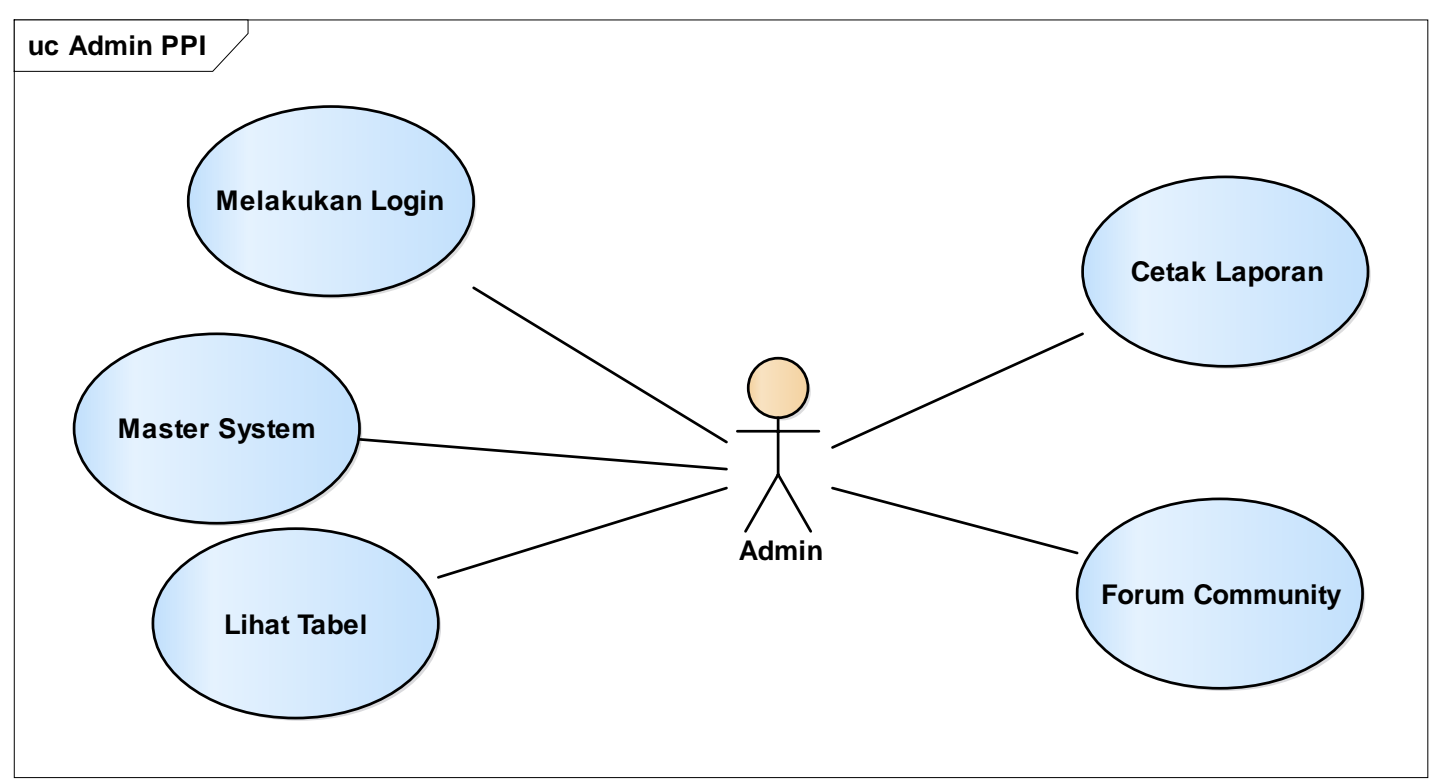

Gambar 1. Use Case Diagram Admin

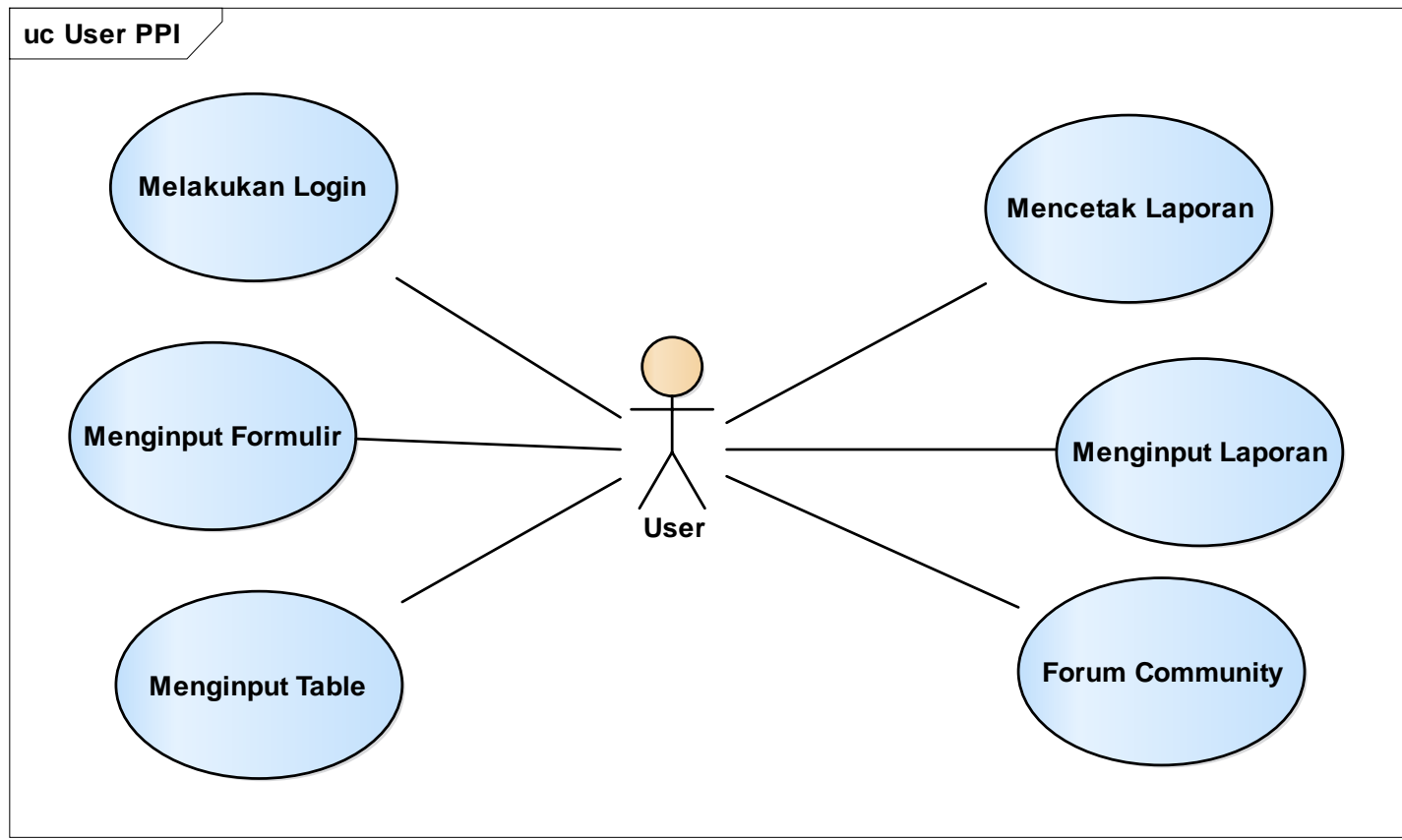

Gambar 2. Use Case Diagram User 


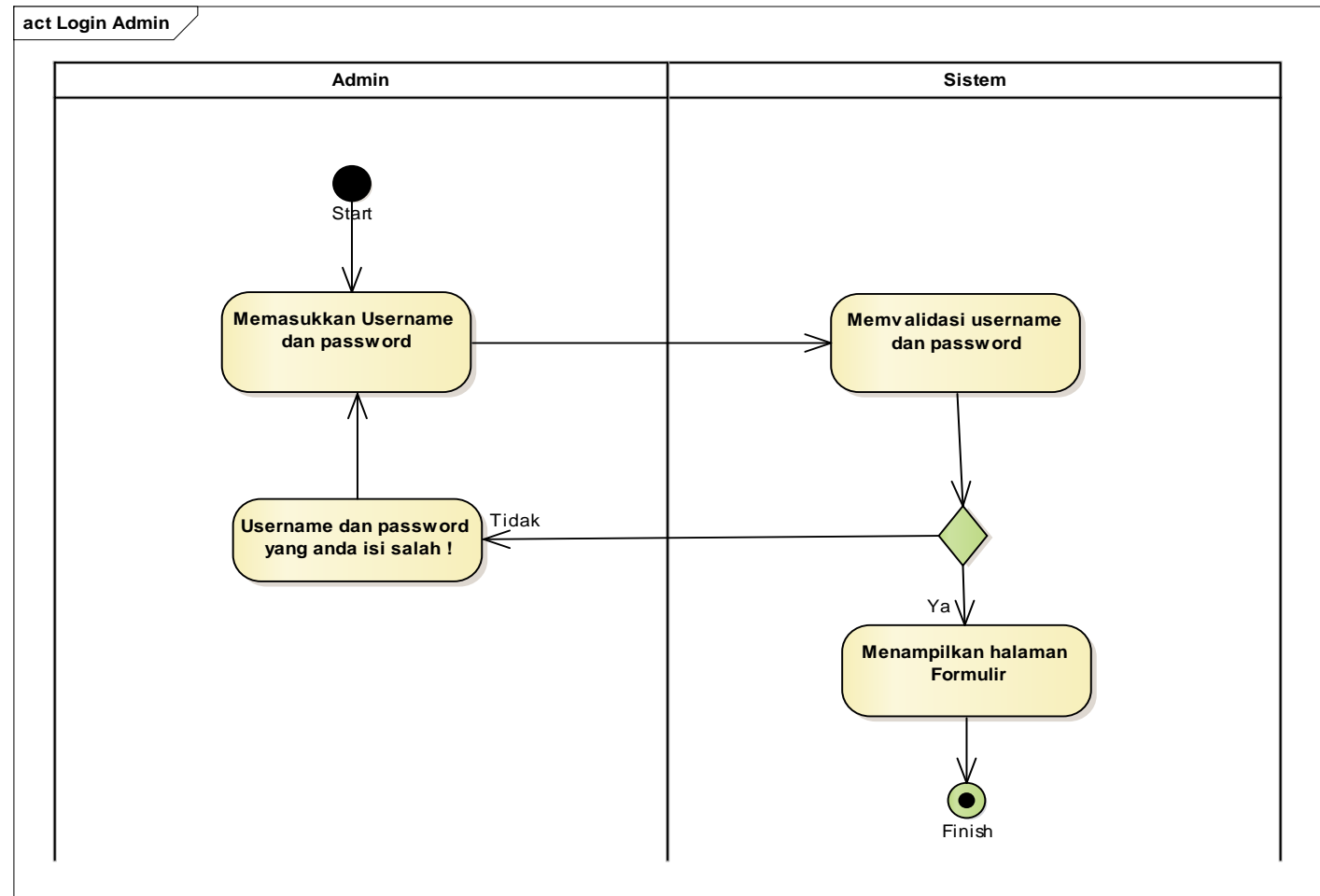

Gambar 3. Activity Diagram Login Formulir

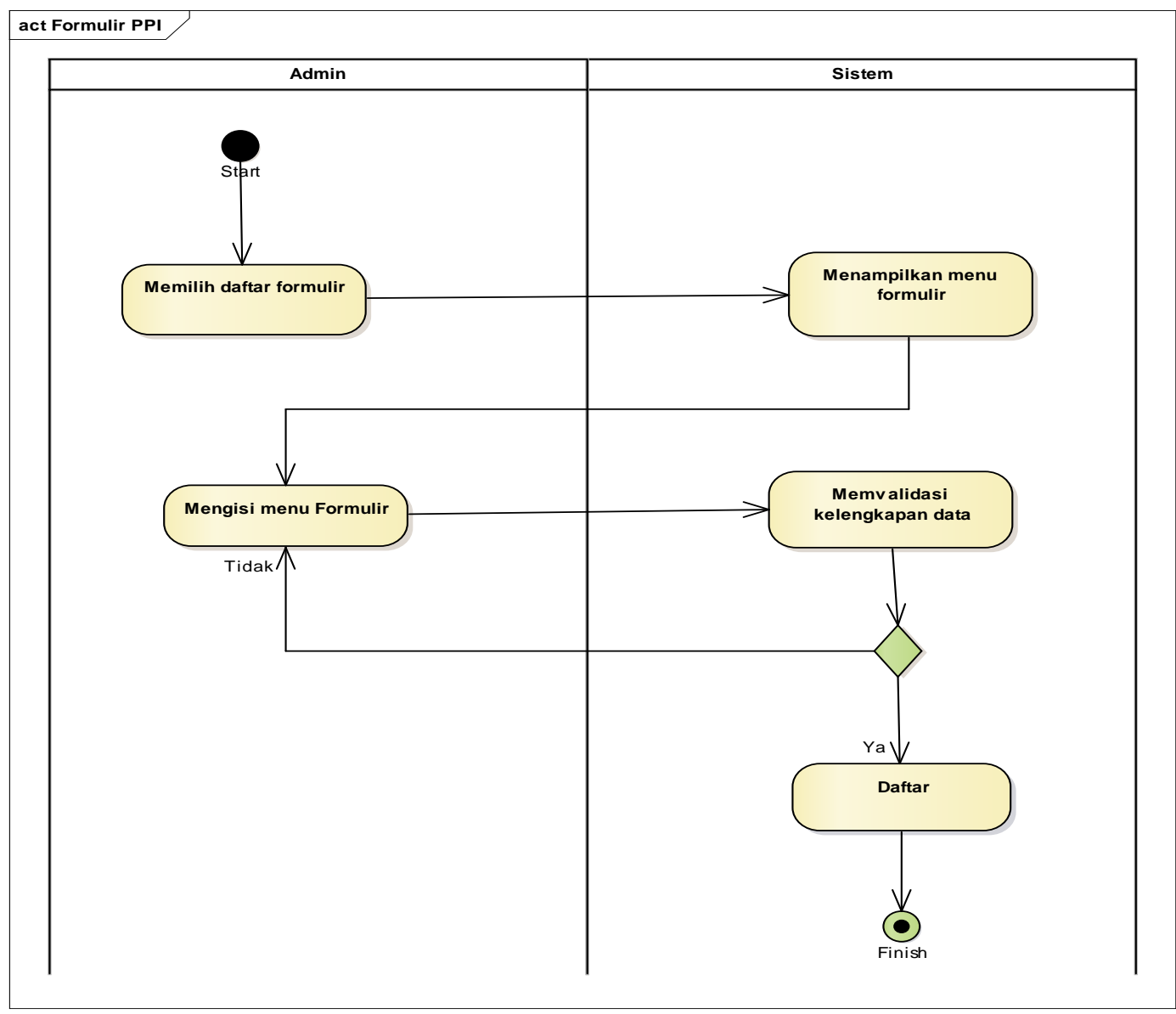

Gambar 4. Activity Diagram daftar formulir 


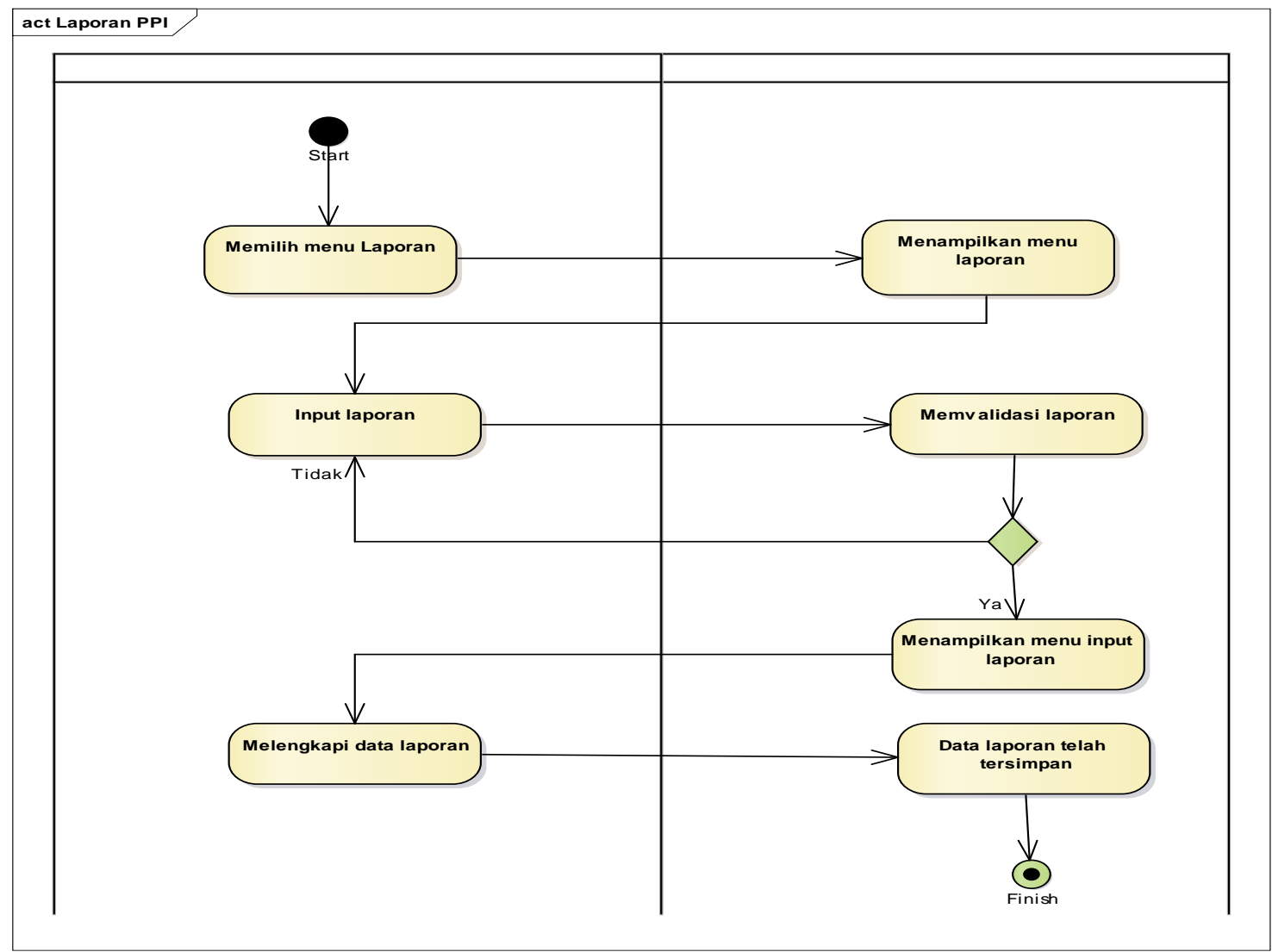

Gambar 5. Activity Diagram Laporan

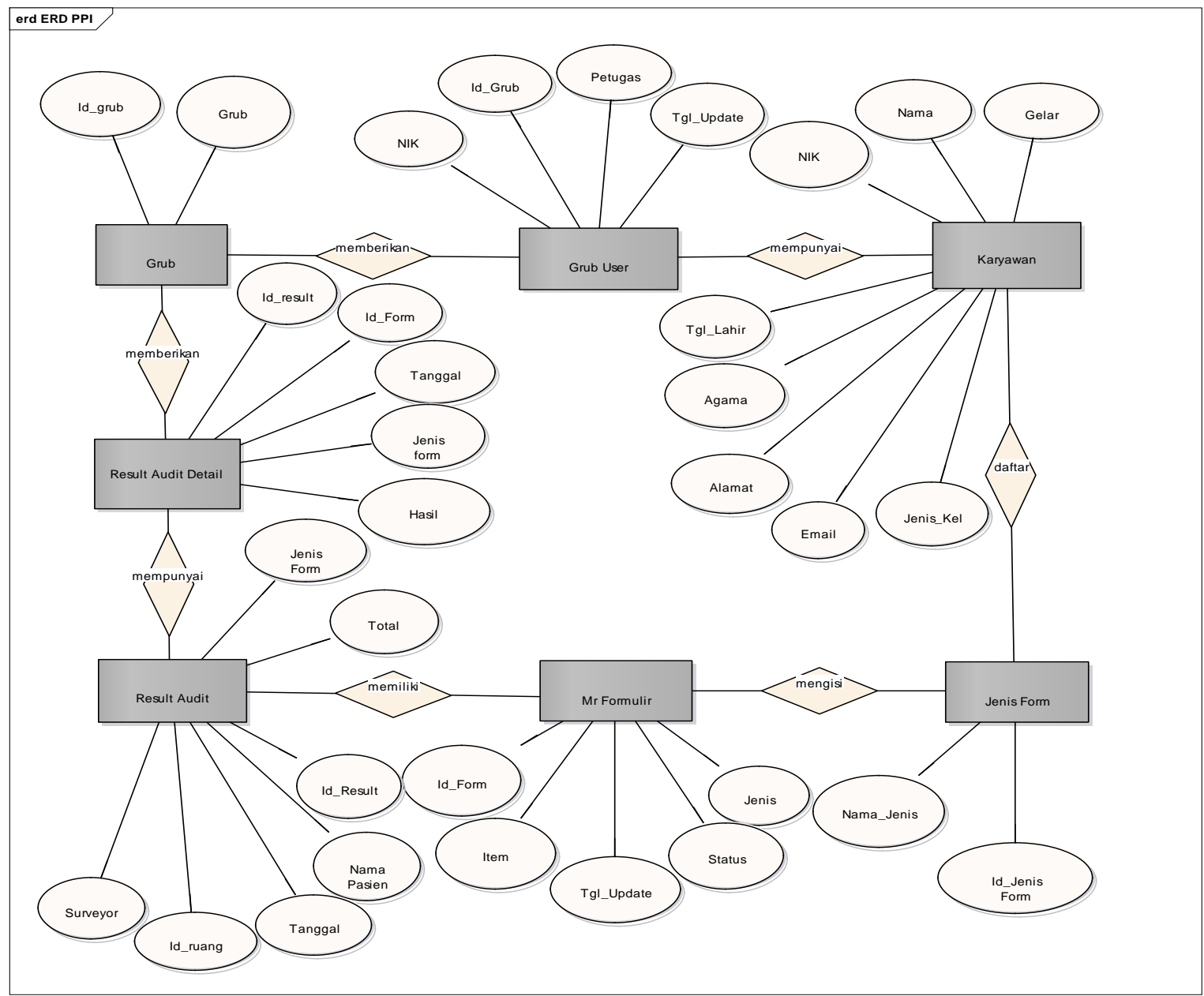

Gambar 6. Entity Relationship Diagram 


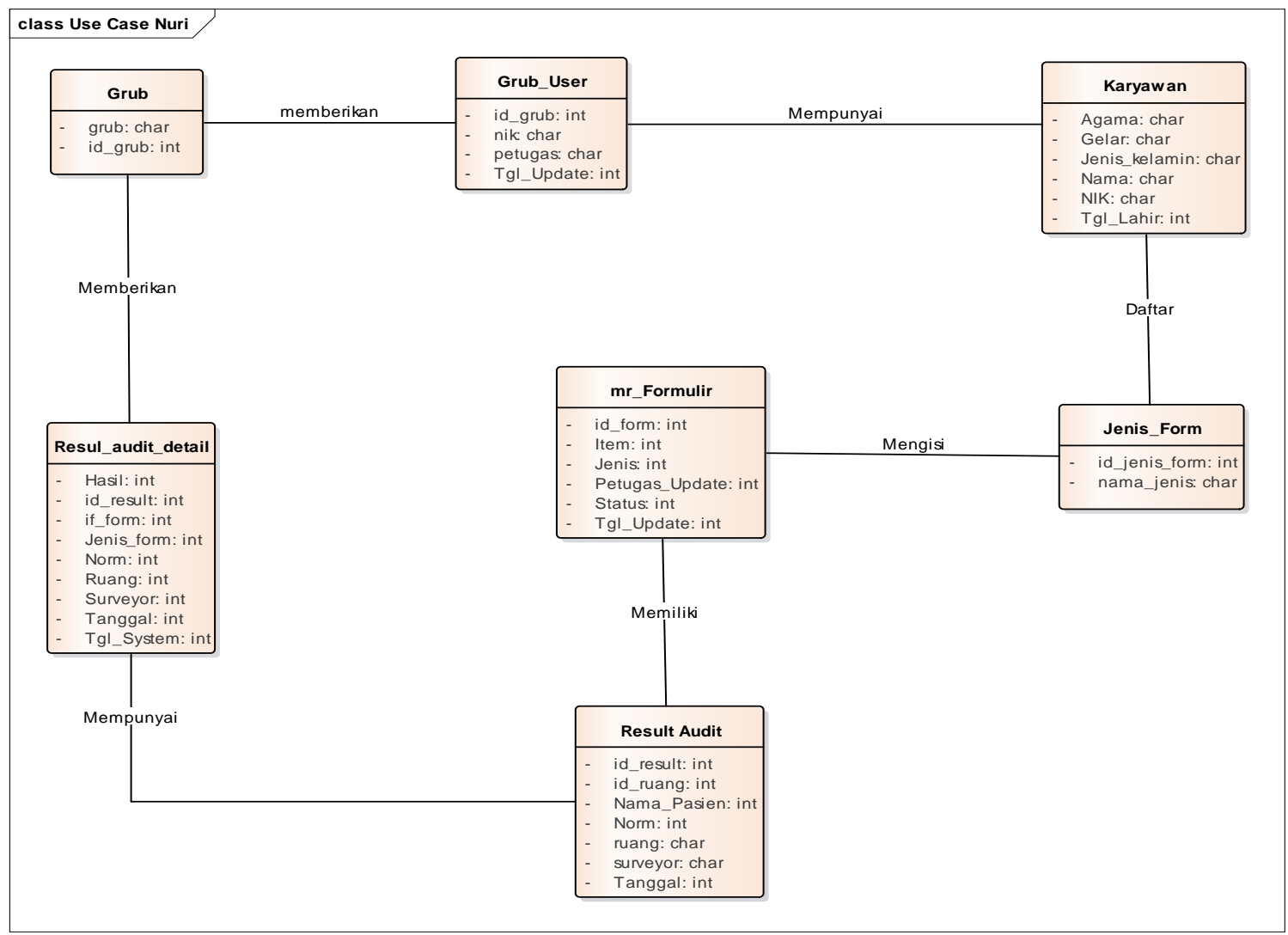

\section{Gambar 7. Logical Record Structure}

Rancangan layar atau userinterface merupakan salah satu komponen dari sistem yang dirancang berfungsi sebagai sarana komunikasi antara user dan program yang nantinya akan digunakan.

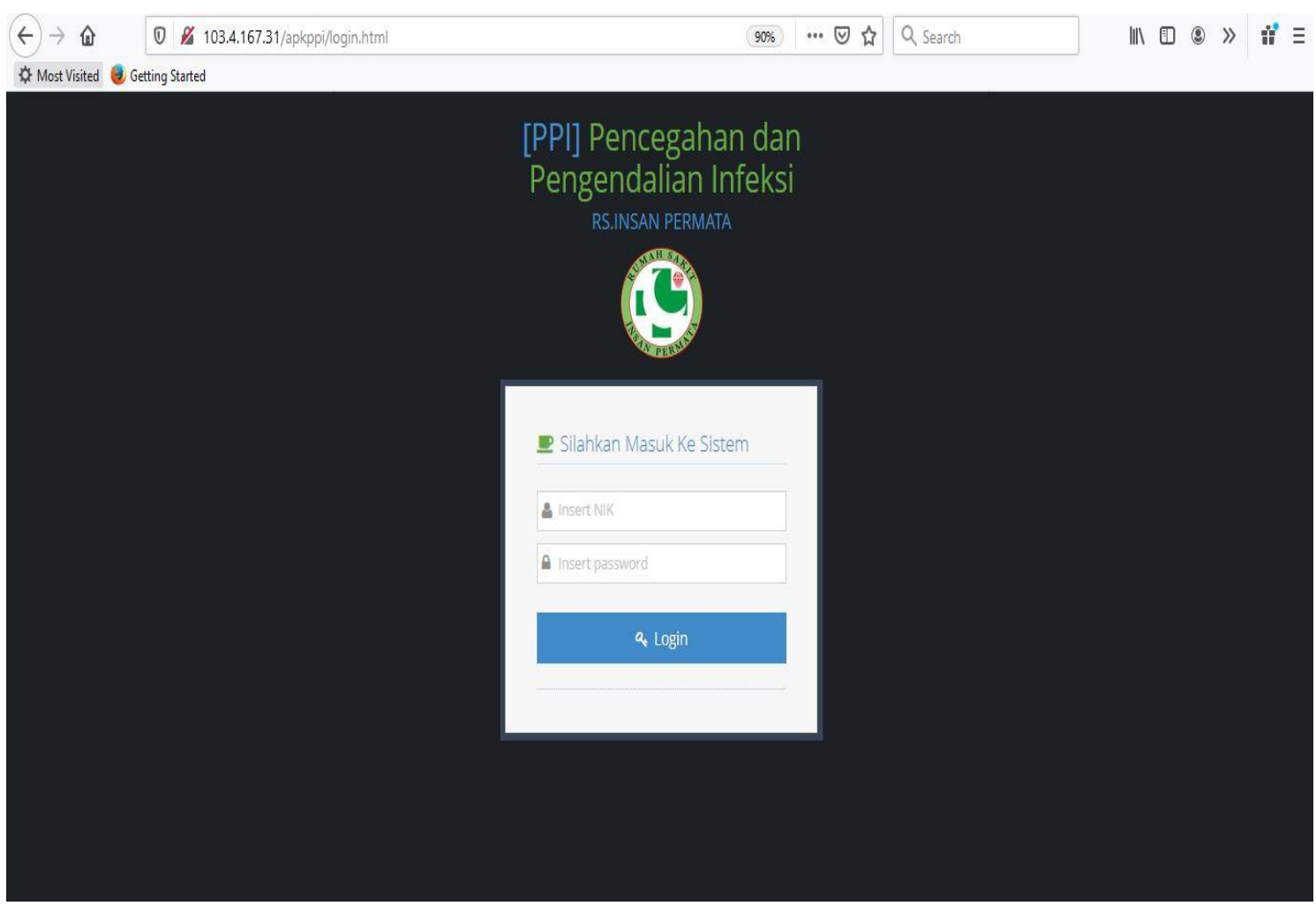

Gambar 8. Halaman Login 


\begin{tabular}{|c|c|c|c|c|c|c|}
\hline \multicolumn{4}{|c|}{ 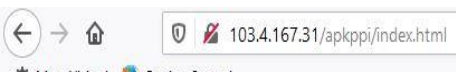 } & $\cdots \odot \hat{\Delta}$ & Q Search & \multirow[t]{2}{*}{ 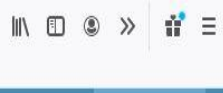 } \\
\hline \multicolumn{6}{|c|}{ Most Visted Getting Started } & \\
\hline \multicolumn{6}{|c|}{ PPI - RS.INSAN PERMATA } & Pengguna \\
\hline$\square$ & Dashboard & $\begin{array}{c}\text { ¿ } \\
\text { Formulir }\end{array}$ & $\begin{array}{l}\text { Leporan } \\
\text { Laporan }\end{array}$ & & & \\
\hline
\end{tabular}

Beranda » sub Judul \& navigation

Selamat Datang, Saudara/ Pengguna

\section{Gambar 9. Halaman Dasboard}

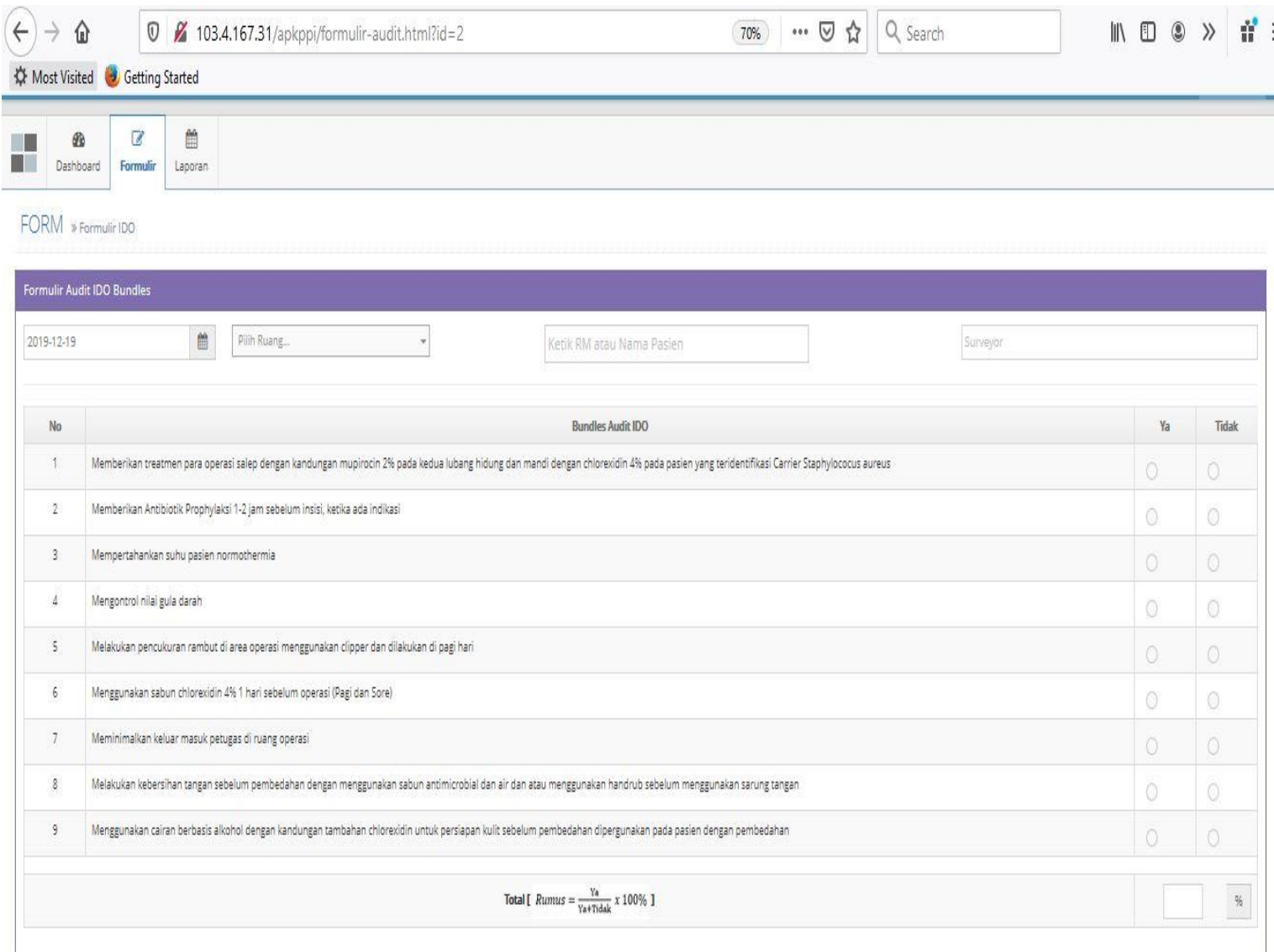

Gambar 10. Halaman Formulir 


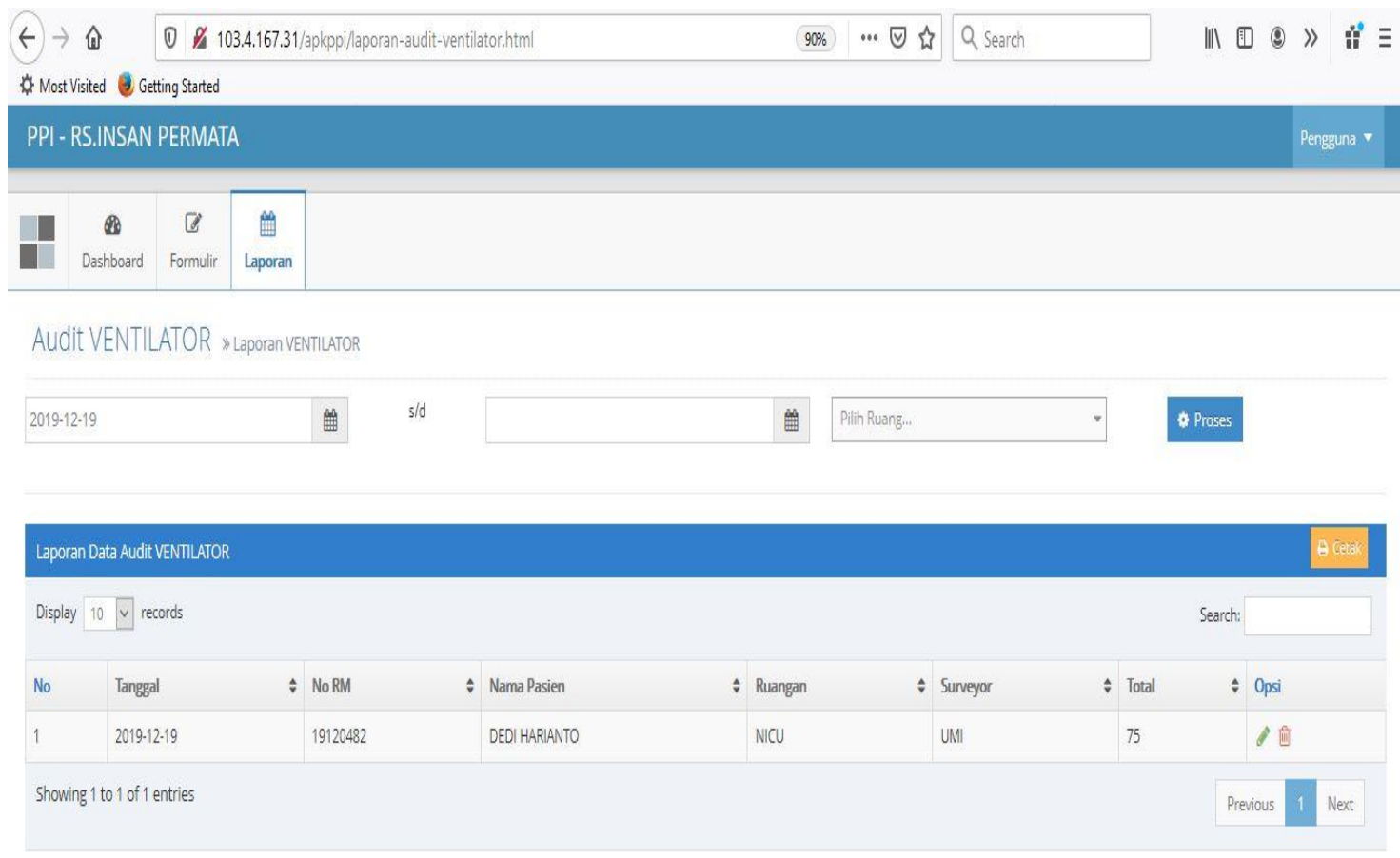

[PPI] RS.Insan Permata (c) 2019

Gambar 11. Halaman Laporan

\section{KESIMPULAN DAN REKOMENDASI}

Berdasarkan hasil pengembangan dari sistem yang telah dilakukan, maka kesimpulan yang diperoleh adalah, Sistem ini dapat menjadi alat untuk membantu mempermudah proses monitoring pasien dan melakukan pendataan. Proses pengumpulan data monitoring surveilens lebih cepat dan proses pendataan juga efesien Proses penyimpanan data sudah menggunakan data base sehingga kemungkinan kehilangan data atau rusak dapat dikurangi. Proses laporan menjadi lebih cepat dengan proses pengumpulan dan proses pendataan yang lebih efesien. Perhitungan Surveilens lebih tepat dan akurat.

Aplikasi ini dirasa masih belum cukup sempurna, masih banyak kekurangan yang masih ditemukan. Supaya hasil kerja yang dihasilkan lebih baik, direkomendasikan untuk meningkatkan keamanan data dari tindakan pembobolan yang menggunakan sql injection maupun aplikasi yg lainnya. Sistem Informasi pencegahan dan penanggulangan infeksi ini bisa digunakan di rumah sakit lainnya karena komite PPI tidak hanya di RSU Insan Pemata. 


\section{REFERENSI}

Anggraeni, E. Y., \& Irviani, R. (2017). Pengantar Sistem Informasi. (E. Risanto, Ed.).Yogyakarta: Penerbit

Andi.Bakhri, S. (2015). Rancang Bangun Sistem Informasi Penjualan Sembako Menggunakan Metode Waterfall, 3(1), 70-82.

Hery. (2012). Pengantar Akuntansi 1. Jakarta: Fakultas Ekonomi Universitas Indonesia.

Muslihudin, M., \& Oktafianto. (2016). Analisis dan Perancangan Sistem Informasi Menggunakan Model Terstruktur dan UML. (A. Pramesta, Ed.). Yogyakarta: Penerbit Andi.

Puspitasari, D. (2015). Rancang Bangun Sistem Informasi Koperasi Simpan Pinjam Karyawan Berbasis Web. Seminar Nasional Ilmu Pengetahuan Dan Teknologi Komputer, XI(2), 186-INF.196.

Rahmawati, M. (2015). Peran Aplikasi Komputer Berbasis Akuntansi untuk Badan Usaha Dalam Persfektif Sistem Informasi, XIII(2), 172-183.

Ramanda, K., Rusman, A., \& Agustin, R. (2017). Rancang Bangun Sistem Informasi Service Center Pada PT . Catur Sukses Internasional Jakarta, 7(2), $1-5$.

Rosa, A. S., \& Shalahuddin, M. (2016). Rekayasa Perangkat Lunak Terstruktur dan Berbasis (Puspitasari, 2015)Objek. Bandung: Informatika.

Syahputra, R., \& Amin, S. (2016). IOS Visual Programming. Yogyakarta: Mediakom. 